\title{
Non-Formal Drama Training For In-Service Language Teachers
}

\author{
Ana Beaven Inma Alvarez
}

\begin{abstract}
Research on the connections between drama and language learning is not new, and interest in the potential collaboration between these fields has increased in the last four decades. However, studies have mostly focused on students' experiences and the type of drama activities that could be incorporated in their language class, neglecting key aspects of the specific skills language teachers might need and how these could be developed. Most language teachers have no training in drama, and often the inclusion of drama activities in the language classroom is dependent on the specific interest and experience of the individual teacher, rather than an expected component of the foreign language training programme. This paper will be reporting on an experimental approach to training inservice language teachers through drama for professional and personal development. As part of a Grundtvig Lifelong Learning European project entitled "Performing languages", experienced language teachers at Higher Education were invited to engage in a series of non-formal activities, including visits to three European countries where they engaged in drama workshops for local amateur groups, reflective methods, and open educational practices.
\end{abstract}

\section{Drama in the language classroom}

Particularly since the 1970s, there has been an increasing interest in the potential links between drama and foreign language teaching. To date, research on the connections between these fields have mostly focused on students' experiences and on methodological approaches and drama activities that could be integrated into the more traditional language lesson (see, for instance, Ballman 2006, 2008; Barnes 1966; Bernal 2007; Bräuer 2002; Dickson 1989; Maley and Duff 1978; Nofri 2011; Ong 2011; Schewe and Shaw 1993).

Common examples of what has been understood as drama-based teaching in this context are the role-plays, simulations and retelling of stories of different kinds into which every language learner is almost inevitably initiated from the very first stages of their learning process. These are mostly set as communicative tasks that aim at facilitating realistic interaction in secondary, and to a lesser 
extent in primary or tertiary education. These drama activities have been used to support the development of all the language macro-skills: reading, listening, writing, speaking and spoken interaction (see, for instance, Faranda 2009).

There have also been more properly 'theatrical' integrations of drama in the language classroom based on the use of actual plays as well as of drama techniques which have given rise to drama pedagogy for language teaching. Plays have been exploited for the purpose of either a performance or for text analysis (Aita 2010; Felske 2005). Techniques have been utilised with the purpose of encouraging an active embodiment of language, which include development of memorisation and improvisation techniques as well as elocution and critical thinking skills (Bernal 2007; Burke and O'Sullivan 2002; McNeece 1983).

Other scholars have also noted, especially since the 1990s, the importance of drama in language education to raise the learners' awareness of cultural contexts and values as well as for developing interculturality (Bräuer 2002). Several of these scholars have suggested the usefulness of an ethnographic approach to language learning with drama at its core. Michael Byram and Michael Fleming (1998) argued that drama in the language classroom has the power to trigger an emotional and reflective approach to the exploration of a foreign culture within a fictional world. More recently, Sonia Cunico (2005) has complained about the lack of an intercultural dimension in language textbooks as well as the invisibility of drama activities to enhance foreign language learning, suggesting that "drama can be approached ethnographically to develop students' intercultural sensitivity and competence" (Cunico 2005: 21). Drawing from the literary tradition, she defends in particular the use of dramatic dialogues from plays because they represent characters from all walks of life in natural conversation and in challenging situations which can be safely replicated in the control context of the classroom. These conversations, she points out, "offer language learning opportunities by widening the range of emotions and experiences students are exposed to in the target language" (Cunico 2005: 28). This means that drama fosters the link between other people's experiences and feelings and one's own. Along a similar line, Katja Frimberger (2009) subsequently argued for the use of a "pedagogy of strangeness" as an ethnographic approach to language education focusing not only on emotions but also on a critical questioning of those emotions via theatre and drama.

Drama in the language classroom has also been considered as an important tool to increase the students' self-confidence, enjoyment, creativity, motivation, empathy and collaborative learning. In addition, experimental research has highlighted that "drama can create community with a group of multicultural and multilingual learners" (Wager et al. 2009: 56).

While ideas for introducing drama in the language classroom and the evidence we have gathered so far about the benefits of doing so are of great interest for educators, in this paper we focus on the language teachers themselves, specifically on the role drama can play in their professional and personal 
development. This is an area we believe to be of crucial importance in order to understand successful and less successful stories of drama-based education.

Some years ago, the Department of Education in the United Kingdom highlighted staff development for teachers as a key area in their cycle of improvement of drama in the English secondary school classroom (Developing drama in English: a handbook for English subject leaders and teachers, 2010). However, this and other official reports, as well as much of the research literature on this topic, do not specify how such training programmes could be implemented, nor what specific skills teachers need in order to introduce drama activities and techniques appropriately at each level of education. Examples of concrete professional development programmes in schools are, for instance, the long-term "Drama for Schools" model in the USA that aims at facilitating change in schools through drama-based instruction for teachers (Dawson, Cawthon, and Baker 2011) ${ }^{1}$, or the "Speaking Out" training project in Singapore teaming up secondary school language teachers with a research team for ongoing professional development in drama pedagogy (Dunn and Stinson 2011; Stinson 2009).

In this paper, we would like to argue, first, that teachers are a key factor in determining the success of drama experiences in language education. If drama can offer a rewarding language and intercultural learning experience in the language classroom, then we need to identify educational possibilities that allow language teachers to use drama. These possibilities could range from language teachers being trained in drama pedagogy and methodology to collaborative formulas of teaching with an emphasis on teachers' complementary expertise. Secondly, we would also like to highlight that currently there is no comprehensive explicit articulation of the transformative impact of artistic practices on the language teachers themselves. Indeed, it has been acknowledged that the impact of drama-based instruction on the pedagogical beliefs of teachers is still under-researched (Lee, Cawthon, and Dawson 2013). Through the project presented here, we intend to point out some of the contributions of these practices.

\section{Non-formal in-service language teacher development}

The landscape of in-service education (INSET) for language teachers in Higher Education (HE) is varied but limited. This is partly because generally HE institutions do not formally support attendance in workshops, seminars and conferences in a systematic manner. One crucial factor is that HE language teachers, at least in the UK, are usually part-time employees, a status which gives them restricted access to funds within their institutions. However, for these, as for all teachers, continuous development is crucial in order to enable them to adapt to their changing roles and responsibilities, but also to foster awareness

\footnotetext{
1 DFS programme webpage: http://www.utexas.edu/finearts/tad/graduate/dramaschools.
} 
of and reflection on their beliefs, values, behaviours, and teaching methods. Ultimately INSET programmes should facilitate any necessary adjustments to professional practices. In this context, the implementation of non-formal opportunities becomes particularly important for in-service language teachers.

Non-formal education (NFE) includes organised activities outside the formal context of learning that offer specific kinds of life-long learning skills; for instance, "[n]on-formal educational activities can take the form of literacy and numeracy classes, cultural activities such as music, dance or drama, sports practices and teams, education regarding child rights or more subject-specific learning" (UNESCO 2006: 214). The concept of NFE has been commonly presented in opposition to formal education or institutionalised education with a defined progression and structure, as well as in contrast with informal learning, which has an emphasis on the activities of the individual learner rather than on an organised educational activity between learner and teacher. There is no current agreement on the definitions of these terms, and Alan Rogers (2004) has pointed out the need to clarify these terms, while suggesting they all are, in fact, part of a continuum (Figure 1).

Rogers bases his understanding of these concepts on a distinction between education and learning, with an emphasis on the idea of who controls the experience. According to his paradigm, in formal education, learners follow a prescribed programme while in non-formal education there is room for the learner to adapt the learning programme to their own needs. This includes flexible schooling constructed by a providing agency but allowing input in specific areas from the actual community of learners. He also includes the concept of participatory education which would be at the other end of formal education and is "very different in spirit and in form" to formal and non-formal education. Participatory education goes further, it is self-directed education where the learner takes an active part in deciding on key aspects of their learning; this type of education takes a place next to informal learning which is fundamentally incidental and unstructured, with no clearly defined outcomes. However, Roger (2004) also acknowledges that elements of all these could be part of the same learning experience.

More specifically, some researchers have studied the value of participating in non-formal artistic practices, arguing how these facilitate learners' development of creative, critical and social skills, as well as risk-taking. Clearly, these also apply to the learning of teachers in any type of training. Again, studies have looked into, for instance, learners' participation in youth communitybased arts centres (Harland, Kinder, and Hartley 1995; Heath, Soep, and Roach 1998), rather than on non-formal artistic practices that could support teachers' development. The importance of attending to teacher development is evidenced, for instance, in studies highlighting that teachers are one of the major arts turn-off (Heath, Soep, and Roach 1998), but that actually teachers' behaviour can be trained through drama (Coppens 2002). Recently, initiatives such as LÓVA (http://proyectolova.es/en/), with a focus on the integration of operatic projects in formal education, have acknowledged explicitly the 
importance of training teachers for the successful delivery of the programme objectives.

In this paper we propose the concept of non-formal training to refer to learning development opportunities for teachers, whether implicit, reactive on-the-spot, or deliberative, that is, unconscious, near-spontaneous or planned learning (Eraut 2000), and argue that this type of training can be crucial in changing the attitudes of language teachers with respect to the inclusion of artistic practices - and more specifically drama - in their professional practice. In the next section we present a European project which explored the potential of a methodological approach to the training of in-service language teachers via a non-formal training model that fostered artistic creation and expressive exchanges in multiple languages with the aim of supporting their professional and personal development.

\section{The Performing Languages project}

Performing Languages (http://performinglanguages.weebly.com) was aEuropean Lifelong Learning project running from August 2011 to July 2013, and funded within the European Union's Grudtvig Programme aimed at Adult Education. It explored the intersection between drama, language learning, intercultural understanding and European identity. ${ }^{2}$ The project included the piloting of a set of non-formal training activities with 13 volunteer experienced language teachers from The Open University in the United Kingdom. Language teachers at the Open University work part-time and at a distance; they teach mostly online and have limited access to staff development events.

The purpose of the project's activities was to raise the teachers' awareness of the different aspects involved in effective language, culture and intercultural communication (Byram, Gribkova, and Starkey 2002) and to provide them with an opportunity to expand their pedagogical repertoire by encouraging them to participate in creative drama interactions. In addition, it placed teachers in a real-life context in which they had to communicate with speakers of other languages.

The specific educational development activities designed for this project included: 1) a series of visits to three European countries (Spain, France, Italy) where UK teachers were invited to engage in local drama workshops led by professional actors for amateur groups; 2) reflective practice, including teaching observations, an activity they were already familiar with as it is practised as a performance management tool in their own HE institution; and 3) collaborative writing of drama-based activities, along with open sharing and critical peer review of these.

In fact, the project engaged teachers with what Schewe (2013) terms "smallscale" and "large-scale forms" of drama-based learning (carried out within one

\footnotetext{
${ }^{2}$ For a project with similar aims but with a focus on young immigrants' engagement in drama activities in French, German and English, see Aden (2010).
} 
single "teaching unit" or stretching longer periods of time). A selection of teachers performed in both intensive, discrete local drama workshops in the hosting countries, which required them "to act verbally and non-verbally [... and] to make use of their linguistic and cultural abilities and knowledge in a variety of ways and also systematically improve on them" (Schewe 2013: 12), but they also had the opportunity to rehearse and finally stage a street performative event which took place in Ferrara, Italy, at the end of the project (Figure 3).

The training programme included coaching and mentoring by three language trainers from the Open University. These trainers were in charge of conducting preparation and follow up sessions before and after the visits, as well as group sessions during the visits. These sessions were an opportunity to discuss and reflect on various aspects of the training including the challenges of drama teaching and learning, the concept of open educational practices, and interaction with the local environment. These sessions also offered the trainers an opportunity to obtain some instant feedback on the programme. Feedback from the participating teachers was also collected via individual interviews. In addition, the teachers' involvement was monitored by their contribution to open educational resources ${ }^{3}$ and by their level of engagement with the visits.

In the next section we will report and reflect on the results of this pilot training. We will focus on the impact of activities related to 1) and 2) above since results from the implementation of point 3 ) have already been published elsewhere (for a detailed account of this point, see Alvarez, Beaven, and Comas-Quinn 2013).

\section{Drama training: From acting out to new teaching practices}

We will now look in detail at the impact of one of the project's deliverables, and specifically the training opportunities (participation in drama activities and reflective methods) offered to language teachers.

The 13 volunteer teachers involved in this project had very little or no formal training in drama or performative events. All but one were women, aged over 40 , with many years of language teaching experience in a variety of languages (Chinese, French, German, Italian, Spanish and Welsh). These practitioners were invited to participate in one of the so-called 'mobilities'-or visits- to three different countries; in order to participate, they had to be learners of the language of the destination country. The degree of commitment of some of the participants can be understood by the fact that four of them found alternative forms of funding in order to participate in more than one visit. The 'mobilities' took place in France in October 2011, in Spain in October 2012, and in Italy in July 2013, and lasted around five days.

\footnotetext{
3 The teachers were encouraged to use the languages repository LORO: http:// / oro. open. ac.uk/.
} 
During these visits, the language teachers had the opportunity to attend a series of drama workshops and cultural events, and visit local places of interest. The workshops were run by local associations for amateur learners under the supervision of professional drama trainers. The activities proposed involved voice and movement exercises, improvisation and acting out imagined situations. In these workshops, the participants could step down from their professional roles, and experience the activities as both language and drama learners (and not teachers), side by side with their local hosts, in a full-immersion context. The aim was thus to establish a line of communication between the participants themselves (both locals and visitors), where an understanding of the context and the emotions involved could develop.

One crucial function of these types of activities is that they support the necessary, but often neglected, link between thoughts, verbal utterances, movement and emotions. Our hope was that experiencing the connection between these aspects would make it more likely that the teachers would draw inspiration from these activities and understand the importance of including them in their teaching practices. During the workshops, the teachers were not required to reflect on how the drama activities could be used in their teaching (this was the focus on another part of the training), but rather to engage with the activities as learners and interact with the local participants. This was not immediately easy to do: most teachers remarked how during the first day's activities they had been unable not to analyse each activity in terms of if and how it could be used in their language lessons, and even the instructor's role and pace of the lessons against their own professional practice. It had required a considerable effort on their part to suspend their beliefs and judgement and experience the activities only as learners.

Er, working with people from outside the discipline for me, I was in completely alien territory. I'd no idea what drama work entailed and it was quite a shock to me, I have to say. (Teacher 1)

Another aspect that was immediately brought up in the interactions between host and guests was an awareness of the sociolinguistic registers that reveal "a set of complementary representations of feelings that are conventionalized among a community of speakers" (Irvine 1990: 127). To this respect, Irvine cites the "complementaires" of the Wolof as contrasting registers, social personae, roles organizing a social situation and roles of transmitter and receptor of the emotion, but defends a perspective that emphasises overall social relations and situations in discourse, that is, "forms of dialogicality" (Irvine 1990: 155). From this approach, emotion is seen as primarily relational, as emerging from relationships between individuals or between them and events. The visits to different countries required the teachers to monitor their emotions and establish relationships with the other participants and according to the development of events in both fictional (drama workshops) and real (cultural events) spheres.

The fictional situations created in some of the activities enabled the participants to widen the range of emotions and experiences expressed in the 
target language, but also to compare these with the way they were expressed in their respective languages. Importantly, this included emotions seldom expressed in the language classroom, such as anger, fear or intimacy. One activity (see Figure 4) required pairs of learners from different linguistic backgrounds and cultures to exchange an appreciative comment, such as "you have beautiful ears" or "wow, that top really suits you!". Although these may be found as part of dialogues in the foreign language classroom, the drama activity required the participants to try out different ways of saying the sentences, from whispering while standing very close to each other, to having to shout the sentence from one end of the stage to the other. The same activity was then repeated with a derogatory comment (such as "have you looked at yourself in the mirror?" or "do me a favour and put on some decent clothes!"), comments which are much more unlikely to be uttered in the foreign language classroom.

In addition, as these were drama and not language activities, the participants could choose the language in which the utterances were delivered (or even try out different languages). They were thus able to explore how emotions are conveyed in different languages, and how this affects their identity construction in the target language. These explorations were made possible in the safety of the fictional space created on stage, while at the same time the participants were able to expand their linguistic and intercultural repertoire usable in real life situations.

This emotional involvement led to another key discovery by the teachers in relation to the workshops: the impact that movement can have on self-expression and consequently on language learning. As one teacher put it:

But another aspect which is, if you like it, very personal is also that I found it quite liberating the fact of moving around and making up stories, go on stage and represent them. I thought it was really great. [...] One reason, for example, is that with movement you memorise the vocabulary. [...] I noticed I was just memorising words which I think is very interesting. So, I think that there is also a lot of potential in languages combined to drama in teaching terms. (Teacher 3 )

A distinct aspect of the language teachers' involvement in the workshops was that, while in this setting the local participants were able to use the acting space as a frame in which they could free themselves from the constraints of real-world interactions, the teachers experienced a more complex situation; they mostly functioned in an overlapping space of drama and ordinary life. Immersed in a multicultural and multilingual context where drama activities were at the centre, the language teachers were confronted with a real-world situation, a social practice (acting out) in which they had to activate their language and intercultural skills at the same level of intensity as in situations outside the theatrical sphere. The drama activities enabled them to experience fictional narratives that connected with the everyday real local events, and to practice on stage different ways of interacting off-stage; also, since these occurred in a foreign country and in interaction with its local people, acting in 
the target language or in multiple languages became a reality for them, both on and off-stage.

As mentioned above, through the drama activities, the participants were required to work on and exteriorise specific emotions, enacting such emotions in ways that might correspond or not with local linguistic and cultural ways. Consequently, the teachers had to draw on their existing linguistic resources, or develop some rapidly when these were not sufficient. At the same time, they also had to bring into play their intercultural skills of interpreting and relating to languages and cultures, as well as the skills of discovery and interaction. To this respect, teachers commented on how the project had enabled them to become aware of cultural differences and of the need to be culturally sensitive to others:

But it's also about getting to know people from a different perspective, you know, understanding that they don't necessarily think the way you do. They have a different culture, different background. And I think it's a combination of the language and the culture really. (Teacher 4)

In relation to this, the teachers spoke of the way in which the drama activities had helped them develop empathic feelings. Aden has suggested that empathy can be considered a skill, "one that underpins inter- and intra-cultural communication" (Aden 2010: 94). The ability to empathise or understand the feeling of others has been described as one of the outcomes of our involvement in drama activities (Smith 1984; Stern 1980), although the point has been made with respect to empathic responses to the characters being played. The empathy teachers referred to in this project extended to the reality of their teaching practices. Teachers reported how being placed in the role of the learner (by taking part in the activities not as teachers, or observers of a teaching practice, but as drama and language learners) made them empathise with feelings of inadequateness, of being lost and not understanding instructions, which students can experience in classroom situations:

I think for me it was, I was very keen to put myself in the students' places, where I think, for all of us at some stage, you know, we found that there were times when [I] couldn't always work out what was expected of us [...] it is always that kind of initial fear that we all experience as students and, as I said, for me it was again one of those incredible times when I could say OK, you know this is how my students feel. (Teacher 1)

Awareness of these critical experiences made the teachers reflect on how they could transform their teaching practices. As the following responses show, they identified, among others, the need to slow down their teaching, make it more enjoyable, more interactive, and to consider different abilities:

... from my teacher perspective, it has enlightened me to use the set of activities in class freely, thinking that, yes, the fun element has to be there because the students learn a lot through response. And also to slow down, I think we all learn that we need to slow down and I have learned that. (Teacher 2) 
... thinking about, you know, using drama in a face-to-face tutorial. And then I also thought, wow, if somebody is very elderly what do you do? And I, well, for example last night I did an activity with an adult class, and before we started the activity I said to them "if you feel that any movement is painful to you please stop, don't follow my instructions". So, maybe something like that needs to be set beforehand. (Teacher 4)

If you embrace something like this where you try to have drama along languages, that really means rethinking, it's a whole process and I am aware of the effort that its required in order to do it.... if you are seriously combining drama and languages, there is quite a lot you can do and explore. (Teacher 5)

During the drama workshops, in turns one teacher always acted as observer. His or her role was to record the drama activities, leaving the other participants free to 'forget' about their professional roles, while enabling the entire group to later discuss the actual experience and the potential for adapting each activity to the specificities of the language classroom. The teachers' reflections focused not only on how to teach, but on the feelings and emotions attached to languages and cultures. There is however a gap between gaining insights into language and culture learning through emotional involvement in drama activities, and the implementation of drama approaches in the languages curriculum. Some authors have referred to the concept of "teacher artistry", a concept that encapsulates teachers' disposition to curiosity, creativity, flexibility, and risk-taking as well as an attitude of tolerance of ambiguity, as a way of achieving best results in education through drama. Dunn and Stinson have emphasized the importance of a well-balanced preparation in both domains language and drama teaching - for the successful realization of this artistry:

When language-learning experiences are planned and implemented by teachers who are aware of the nuances of both language learning and drama learning, then the results achieved will be optimized. (Dunn and Stinson 2011: 630)

The training provided in the context of the Performing Languages project had the effect of highlighting for the participant teachers the potential of getting that balance right, but was clearly not sufficient to transform them into proficient artists. A realistic programme should acknowledge that the complexities of reaching a good level of artistry might take a substantially longer period of training than could be provided in this project.

\section{Conclusions}

The Performing Languages project aimed at providing a small group of language teachers with a non-formal training experience by enabling them to take part in a series of drama workshops for amateur actors so that they could expand their teaching repertoire, but also become aware of themselves as agents 
in a multilingual and multicultural society. By getting involved in intensive collaborative learning, artistic creativity, and intercultural encounters, they were offered the possibility to experience, practice and reflect on unfamiliar teaching techniques and methods, and to create relevant resources for their own teaching context. At the same time, the teachers took part in real interpersonal experiences in an international context, through which they had the opportunity to feel language learners again, and to become aware of the different aspects involved in effective, expressive intercultural communication.

In this paper we have highlighted how language education research has been mostly preoccupied with the learners, and how there is scope for further studies on the needs of language teachers with respect to non-formal training opportunities. We have focused in particular on how drama-based pedagogy can support professional and personal development.

Time will show the long-term effect of this training on the teachers involved, and whether any lasting changes were achieved. The short-term impact of this non-formal INSET intervention is evidenced by the teachers' feedback, concerning, for example, their awareness of the emotional dimension of drama for language teaching -and their actions- in their active engagement with open practices. The learning activities which the teachers developed collaboratively as well as independently during and after the training have been shared via an open repository. In addition, some of the teachers have enrolled in amateur drama courses, and have disseminated their new skills by imparting workshops and seminars to their local peers.

Future studies could focus on the impact this training has had on these language teachers not only at a professional but also at a personal level. In addition, it will be worth investigating the specific contributions of this type of training to a distance teaching context. Teachers at the Open University teach disperse groups of students, which requires that many teaching sessions be conducted online. The drama resources language teachers have shared so far reflect their personal experiences of implementing drama-based activities in their face to face lessons; however, one of the specific challenges they will have to face is how to apply drama pedagogy in their virtual lessons.

A recommendation from this training experience would be to seek more non-formal alliances between drama practitioners and language teachers in both face-to-face and virtual contexts.

Finally, although this training focused on Higher Education language teachers of adult learners, we believe that the methods of training reported here are also relevant for language teachers and assistants in secondary or primary schools.

\section{Bibliography}

Aden, Joëlle (2010): An intercultural meeting through applied theatre. Berlin: Schibri-Verlag 
Aita, Sean (2010): Performing England: Language and Culture in Performative Praxis. In: Research in Drama Education 15/3, 361-384

Alvarez, Inma; Beaven Tita \& Comas-Quinn, Anna (2013): Performing languages: an example of integrating open practices in staff development for language teachers. In: Journal of e-Learning and Knowledge Society 9/1, 85-92

Ballman, Terry L. (2006): To Speak or Not to Speak?: Drama Techniques, Narration and Other Real-Life Activities. In: Hispania: A Journal Devoted to the Teaching of Spanish and Portuguese 89/2, 366-368

Ballman, Terry L. (2008): Drama or No Drama? That Is the Question. In: Hispania: A Journal Devoted to the Teaching of Spanish and Portuguese 91/1, 233-234

Barnes, Douglas (1966): Drama in the English classroom. Paper read at Papers relating to the Anglo-American seminar on the teaching of English, 1968, at Dartmouth College

Bernal, Penny (2007): Acting out: Using Drama with English Learners. In: The English Journal 96/3, 26-28

Bräuer, Gerd (2002): Body and Language. Intercultural Learning Through Drama. Westport, Connecticut / London: Ablex Publishing

Burke, Ann F. \& O'Sullivan, Julie C. (2002): Stage by Stage: A Handbook for Using Drama in the Second Language Classroom. Portsmouth, NH: Heinemann

Byram, Michael; Gribkova, Bella \& Starkey, Hugh (2002): Developing the intercultural dimension in language teaching. A practical introduction for teachers. Strasbourg: Council of Europe

Coppens, Henriette (2002): Training Teachers' Behaviour. In: Research in Drama Education: The Journal of Applied Theatre and Performance 7/2, 195-206

Cunico, Sonia (2005): Teaching Language and Intercultural Competence through Drama: Some Suggestions for a Neglected Resource. In: Language Learning Journal 31/1, 21-29

Dawson, Kathryn; Cawthon, Stephanie W. \& Baker, Sally (2011): Drama for Schools: teacher change in an applied theatre professional development model. In: Research in Drama Education: The Journal of Applied Theatre and Performance 16/3, 313-335

Developing drama in English: a handbook for English subject leaders and teachers (2010): edited by Department of Education. United Kingdom.

London: Crown

Dickson, Patricia S. (1989): Acting French: drama techniques in the second language classroom. In: The French Review 63/2, 300-311

Dunn, Julie \& Stinson, Madonna (2011): Not without the art!! The importance of teacher artistry when applying drama as pedagogy for additional 
language learning. In: Research in Drama Education: The Journal of Applied Theatre and Performance 16/4, 617-633

Eraut, Michael (2000): Non-formal learning and tacit knowledge in professional work. In: British Journal of Educational Psychology 70/1, 113-136

Faranda, Lidia (2009): Drama activities for language teachers. Powerful strategies for engaging LOTE students. Edited by Department of Education. Sydney: AFMLTA

Felske, Claudia Klein (2005): Beyond the Page: Students as Actor-Readers. In: The English Journal 95/1, 58-63

Frimberger, Katja (2009): Towards a pedagogy of strangeness. In: Scenario III/1: 17-28

Harland, John; Kinder, Kay \& Hartley, Kate (1995): Arts in their view: study of youth participation in the arts. Slough: National Foundation for Educational Research

Heath, Shirley; Soep, Brice, E. \& Roach, Adelma (1998): Living the arts through language-learning: a report on community-based youth organisations. In: Americans for the Arts 2/7, 1-20

Irvine, Judith T. (1990): Registering affect: heteroglossia in the linguistic expression of emotion. In: Lutz, Catherine A. \& Abu-Lughod, Lila (ed.): Language and the politics of emotion. Cambridge: Cambridge University Press

Lee, Bridget; Cawthon, Stephanie \& Dawson, Kathryn (2013): Elementary and Secondary Teacher Self-Efficacy for Teaching and Pedagogical Conceptual Change in a Drama-Based Professional Development Program. In: Teaching and Teacher Education: An International Journal of Research and Studies 30, 84-98

Maley, Alan \& Duff, Alan (1978): Drama Techniques in Language Learning. Cambridge: Cambridge University Press

McNeece, Lucy Stone (1983): The Uses of Improvisation: Drama in the Foreign Language Classroom. In: The French Review 56/6, 829-839

Nofri, Carlo (2011): Guía del método GlottoDrama. Aprendizaje de lenguas extranjeras a través del teatro. Translated by Antonella Mele. Edited by Departamento de Lingüística Aplicada CAMILLE. Valencia: Novacultur

Ong, Rachel Jingyun (2011): Drama! An Exciting Way to Engage English Language Learners. In: Illinois Reading Council Journal 39/4: 24-27

Rogers, Alan (2004): Looking again at non-formal and informal educationtowards a new paradigm. In: The encyclopaedia of informal education. Available from: http://infed.org/mobi/looking-again-at-non-formaland-informal-education-towards-a-new-paradigm/ (Accessed 15 March 2014) 
Schewe, Manfred (2013): Taking stock and looking ahead: Drama pedagogy as a gateway to a performative teaching and learning culture. In: Scenario VII/1: 5-27

Schewe, Manfred \& Shaw, Peter (1993): Towards drama as a method in the foreign language classroom. Frankfurt am Main: Peter Lang

Smith, Stephen M. (1984): The theater arts and the teaching of second languages. Reading, MA: Addison-Wesley

Stern, Susan (1980): Drama in second language learning from a psycholinguistic perspective. In: Language Learning 30/1: 77-100

Stinson, Madonna (2009): 'Drama is like reversing everything': intervention research as teacher professional development. In: Research in Drama Education: The Journal of Applied Theatre and Performance 14/2: 225-243

UNESCO (2006): Chapter 2.9 Non-formal education. Section 3: Teachers and learners. In: Guidebook for planning education in emergencies. Paris:

International Institute for Educational Planning, 213-237

Wager, Amanda, Belliveau, George, Beck, Jaime \& Lea, Graham W. (2009):

Exploring drama as an additional language trhough research-based theatre. In: Scenario III/ 2: 49-64 